\title{
Simulation of Acoustics for Ares I Scale Model Acoustic Tests
}

\author{
Gabriel C. Putnam \\ All Points Logistics - Jacobs, MSFC / ER42 \\ MSFC, AL, 35812 \\ 256-544-9577 \\ gabriel.c.putnam@nasa.gov \\ Louise L. Strutzenberg \\ Marshall Space Flight Center, MSFC / ER42 \\ MSFC, AL, 35812 \\ 256-544-0946 \\ louise.s@nasa.gov
}

The Ares I Scale Model Acoustics Test (ASMAT) is a series of live-fire tests of scaled rocket motors meant to simulate the conditions of the Ares I launch configuration. These tests have provided a well documented set of high fidelity acoustic measurements useful for validation including data taken over a range of test conditions and containing phenomena like Ignition Over-Pressure and water suppression of acoustics. To take advantage of this data, a digital representation of the ASMAT test setup has been constructed and test firings of the motor have been simulated using the Loci/CHEM computational fluid dynamics software. Results from ASMAT simulations with the rocket in both held down and elevated configurations, as well as with and without water suppression have been compared to acoustic data collected from similar live-fire tests. Results of acoustic comparisons have shown good correlation with the amplitude and temporal shape of pressure features and reasonable spectral accuracy up to approximately $1000 \mathrm{~Hz}$. Major plume and acoustic features have been well captured including the plume shock structure, the igniter pulse transient, and the ignition overpressure. 